\title{
Sexually Dimorphic Effects of Aging on Rat Somatotropes and Lactotropes
}

\author{
Giovanni L. Rossi, ${ }^{1}$ Gilberto E. Bestetti, ${ }^{1}$ Enrico Galbiati, ${ }^{2}$ \\ Eugenio E. Müller, ${ }^{3}$ and Daniela Cocchi ${ }^{3}$
}

\author{
'Division of Experimental Pathology, Institute of Animal Pathology, University of Berne, Switzerland. \\ ${ }^{2}$ Fidia Research Laboratories, Abano Terme, Italy. \\ ${ }^{3}$ Department of Pharmacology, University of Milan, Italy.
}

\begin{abstract}
During the aging process modified functions of hypothalamic factors may cause sexually dimorphic changes in pituitary somatotropes and lactotropes. To test this hypothesis, pituitary tissue from young adult (4 months) and old $(20-22$ months) male and female rats was labeled immunocytochemically for growth hormone $(G H)$ and prolactin (PRL). The total amount of immunoreactive material as well as the total area and number of immunoreactive structures were evaluated. With increasing age the intracellular $\mathrm{GH}$ content was moderately increased in male and decreased in female rats. An age-dependent PRL increase, due both to increased cell number and intracellular hormone content, was present only in female rats. The amount of $\mathrm{GH}$ - and PRL-immunoreactive material, distributed into classes of increasing density, differed both between sex and age groups. Our results indicate that the aging process of the somatotrope and lactotrope cell populations in rats appears to be different in the two sexes.
\end{abstract}

$S^{\mathrm{E}}$ EVERAL important age-related alterations in rodents are primarily caused by impaired neuroendocrine functions (Meites, 1986). These in turn are due to altered cerebral neurotransmitters which, together with hypophysiotropic neuropeptides, mainly regulate the endocrine system (Müller et al., 1977).

Aging severely impairs hypothalamic dopamine (DA) and norepinephrine function (Simpkins et al., 1977; Pradahan, 1980). This leads to progressively reduced gonadotropin and growth hormone $(\mathrm{GH})$ and increased prolactin (PRL) secretion from the pituitary gland (Meites, 1986).

Progressively reduced $\mathrm{GH}$ secretion and in vivo $\mathrm{GH}$ responsiveness to physiological GH-releasing hormone (GRF) are evident in aging rodents (Sonntag et al., 1983; Cocchi et al., 1986) as well as in man (Rudman et al., 1981; Sonntag et al., 1983; Shibasaki et al., 1984). Also, the amount of immunoreactive GRF present in the median eminence of old rats is markedly reduced, while immunoreactive somatostatin is almost unchanged (Morimoto et al., 1988). Further, pituitaries of old rats contain less GH and secrete in vitro less GH than those of young rats (Cocchi et al., 1986). Finally, in somatotropes from male and female rats the responsiveness to GRF, measured by GH secretion and by adenylate cyclase stimulation, is lower in old than in young animals (Parenti et al., 1987).

In old female rats, which often bear PRL-secreting tumors (Kovacs et al., 1977; Berkvens et al., 1980), the plasma PRL level (Cocchi et al., 1986; Meites, 1986) and number of lactotropes (Takahashi and Kawashima, 1982; Chuknyiska et al., 1986) are increased. Although the inhibitory activity of the tuberoinfundibular dopaminergic system is comparably reduced in both sexes, plasma PRL levels of old male rats remain within a normal range (Forman et al., 1981; Cocchi et al., 1986).

Age-related modifications of the secretion and/or function of GRF or DA may partially be responsible for the different hormonal pattern in the two sexes. Besides regulating target cells, GRF and DA also control cell replication (Davies et al., 1974). Hence, the somatotrope and lactotrope cell populations presumably vary in the two sexes during the aging process.

To test this hypothesis, we evaluated by morphometry and densitometry immunocytochemically labeled somatotropes and lactotropes from young adult and old rats of both sexes.

\section{MATERIALS AND METHODS}

General. - Twenty-eight young adult (4 months) and old (20-22 months) male and female Sprague-Dawley rats (Charles River, Calco, Italy) were used in this study ( 7 rats per group: young adult male, young adult female, old male, old female). They were housed under controlled conditions $\left(22^{\circ} \pm 2^{\circ} \mathrm{C}, 65 \%\right.$ humidity and artificial light from 0600 $2000 \mathrm{~h}$ ) with standard pellet food and water available ad libitum.

At the end of the experiment the rats were anesthetized by ketamine hydrochloride (200 mg/kg BW i.p.) and perfused by $2 \%$ glutaraldehyde- $1.5 \%$ paraformaldehyde fixative so-

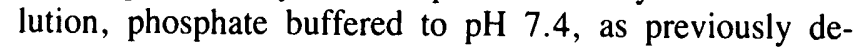
scribed (Rossi and Bestetti, 1983).

Subsequently the skulls were opened and the whole brains and pituitary glands removed and weighed. Each pituitary gland was then cut into two halves by a sagittal section, and from each side a standard symmetrical strip about $0.5 \mathrm{~mm}$ thick, containing the three main pituitary regions, was used. Embedding in Spurr's low viscosity medium followed.

Immunocytochemistry and densitometry. - Semithin sections were cut and processed for GH and PRL immunocytochemistry using rabbit anti-human GH (Dako Corporation, 
Santa Barbara, CA) diluted 1:500 and anti-human PRL (Dako Corporation) diluted 1:200 with PBS and goat anti-rabbit alkaline phosphatase (Sigma Chemical, St. Louis, MO) as previously described (Bestetti et al., 1987). To ensure reliable quantitative data, all tissue sections were checked for constant thickness by measuring micrometrically the section edge at high magnification. In addition, two sets of sections (one from a young adult, the other one from an old rat) were mounted on the same slide, and all slides were processed as a single batch. Method controls involved omission of antisera or preabsorption of antisera with specific purified rat hormones according to the protocol of Lloyd and Childs (1988).

After a preliminary observation by conventional light microscopy (Figures $\mathbf{I}$ and 2), the immunoreactive material present in the sections was quantified as described by Childs et al. (1987), with some personal modifications. Briefly, the measuring procedure was as follows: the microscopical fields to be studied were captured with a television camera, digitized, and projected on the monitor screen of an automatic image-analysis system (DIASYS, Datalab, Thörigen, Switzerland). The densitometer was calibrated daily to grant constant conditions throughout the experiment. The light setting was constant for each measuring series ( 240 lux). To improve contrast an infrared, a dark green, and a gray (Zeiss $0.5)$ filter were used. The images were taken by a $20 \times$ objective. The black-and-white television camera transferred the microscopic image to a screen upon which a digitized cursor was electronically generated. The instrument was initially calibrated in the gray level analysis mode (128 gray levels) by determining the gray level (density) of a predetermined clear (gray 127) and dark (gray 1) region of a standard section. After careful focusing, the recording of the image induced the automatic digitizing function with: calculation of a mean image from three subsequently digitized images, subtraction of a previously set background image, gray calibration, and image inversion. Two standard sections, one from the left, the other from the right lobe, were measured in each animal. Specific areas were then selected by setting windows. Four windows, $0.11 \mathrm{~mm}^{2}$ each (corresponding to about 500 pituicytes) per section, not overlapping and covering a representative portion of the anterior lobe were measured. The number of pixels activated by the label in each structure was read and calculated by the computer microdensitometer. For each field threshold values for label detection were separately preset so that the computer would read only the label present in the selected structures.

We obtained the following measurements: (a) number of pixels per gray level; (b) number of labeled anatomical structures (contiguous areas of the image exceeding a particular density); and (c) total area of the immunoreactive substance. The number of GH-labeled structures roughly corresponds to the number of somatotropes when these cells are not clustered and becomes progressively lower with increasing formation of cell clusters (Figure 1, A-D). The number of PRL-labeled structures is generally higher than the number of lactotropes, since PRL secretory granules are usually present in the cell in several cytoplasmic regions (Figure 2, A-D), but becomes somewhat lower with increasing formation of cell clusters. We subsequently calculated: (a) total number of pixels in each gray level; (b) sum of the product of the number of pixels times the corresponding gray level [this sum, which we named "total immunoreactivity," is considered a relative quantitative evaluation of the antigen content (Agnati et al., 1988)]; (c) ratio of total immunoreactivity to area of immunoreactive structures; and (d) distribution of pixels into classes of increasing gray level.

Statistical analysis. - Group means and standard errors (SEM) were calculated. The significance of differences between groups was tested with the Student's $t$ or the MannWhitney-Wilcoxon $U$ test, depending upon normality of distribution. The significance of differences between distributions was tested with the chi-square test.

\section{RESULTS}

General. - Body, brain, and pituitary weights are reported in Table 1. The pituitary weight was higher in old than in young adult animals of both sexes and higher in old female than in male rats. The brain weight was higher in old than in young adult female rats.

Immunocytochemistry of somatotropes. - By light-microscopical observation no adenomatous change was observed. GH-immunoreactive cells appeared to be more numerous both in old (Figure 1B) than in young (Figure 1A) male as well as in young (Figure IC) than in old (Figure 1D) female rats. Compared with female, male rats of both age groups appeared to have more immunolabeled cells.

By densitometrical $\mathrm{GH}$ evaluation, the total immunoreactivity $(p<.05)$ and ratio of total immunoreactivity to area of immunoreactive material per unit area of tissue $(p<.01)$ were higher in old than in young adult male rats (Table 2). Compared with young, in old male rats also the distribution of pixels into classes of increasing gray level (Figure 3, A,B) was shifted toward classes of higher density $(p<.01$ young adult vs old). The number of immunoreactive structures, on the contrary, was lower $(p<.01)$ in old than in young adult male rats (Table 2).

The total immunoreactivity $(p<.05)$ and area of immunoreactive material per unit area of tissue $(p<.01)$ were lower in old than in young adult female rats (Table 2). Compared with young, in old female rats the number of immunoreactive structures, on the contrary, was decreased $(p<.01$; Table 2). Also, the distribution of pixels into classes of increasing gray level (Figure 3, C,D) showed that no pixels were present in the first 6 classes $(p<.01$ young adult vs old). The ratio of total immunoreactivity to area of immunoreactive material per unit area of tissue was increased $(p<.01$; Table 2$)$.

By comparing the two sexes (Table 2), the total GH immunoreactivity, the number of immunoreactive structures, and area of immunoreactive material per unit area of tissue were higher $(p<.01)$ in old male than in old female rats. Also, the distribution of pixels into classes of increasing gray level (Figure 3, B,D) showed that in all classes the total number of pixels was clearly lower $(p<.01)$ in old female rats. The ratio of total immunoreactivity to area of immuno- 


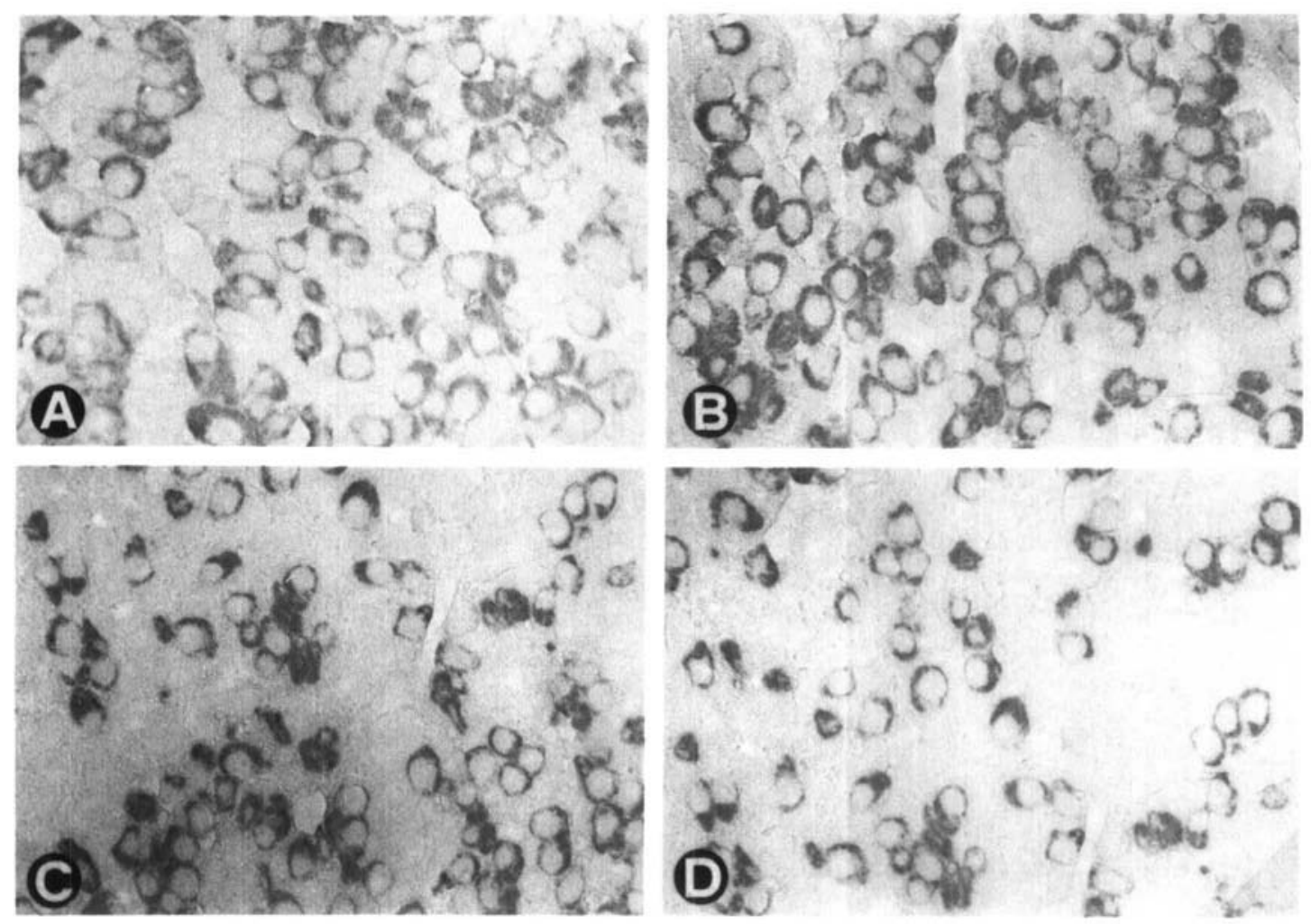

Figure 1. Immunocytochemical demonstration of growth hormone (A-D) in representative sections of anterior pituitary glands of young adult (A) and old (B) male and of young adult (C) and old (D) female rats. $330 \times$.
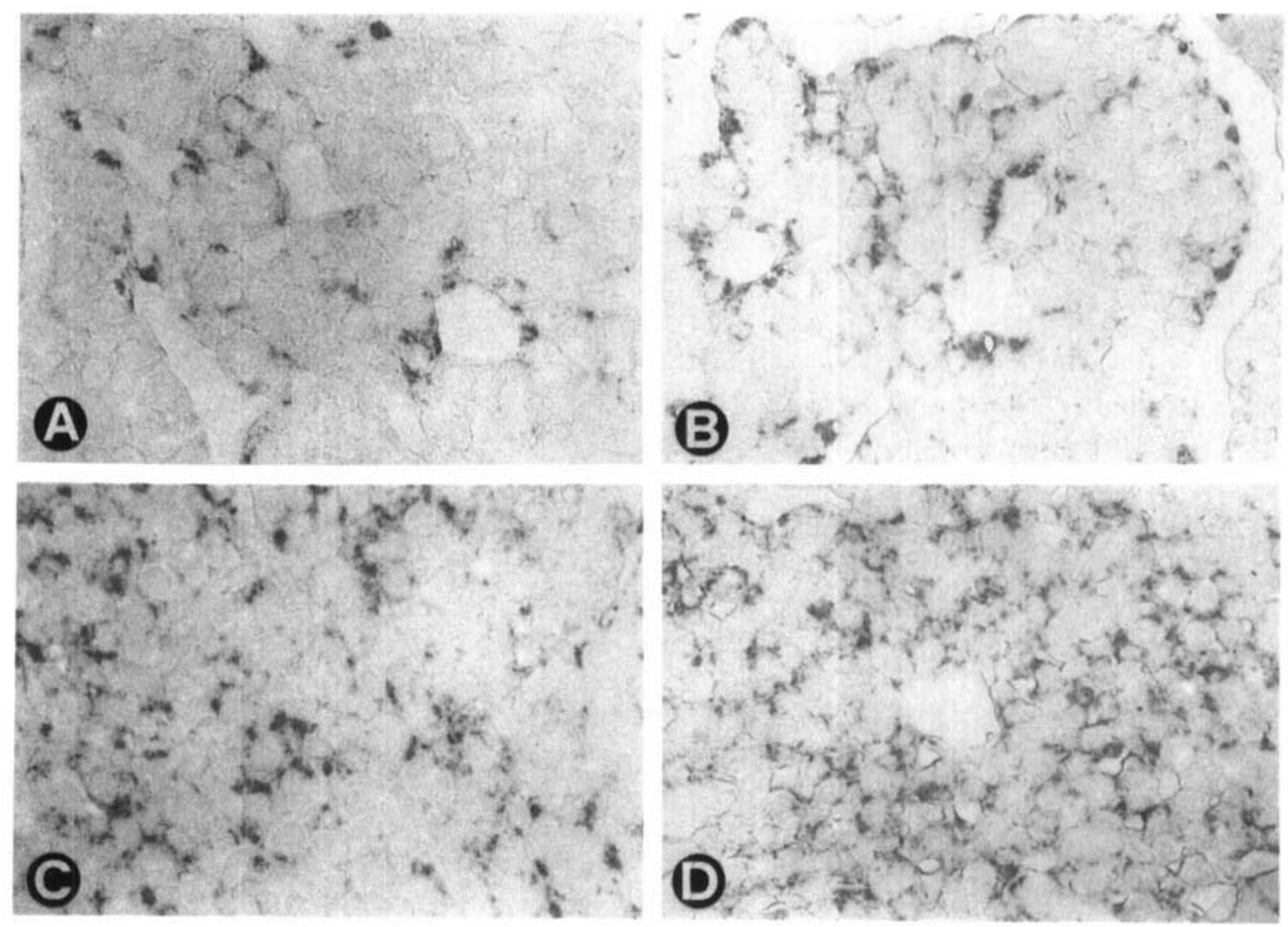

Figure 2. Immunocytochemical demonstration of prolactin (A-D) in representative sections of anterior pituitary glands of young adult (A) and old (B) male and of young adult (C) and old (D) female rats. $330 \times$. 


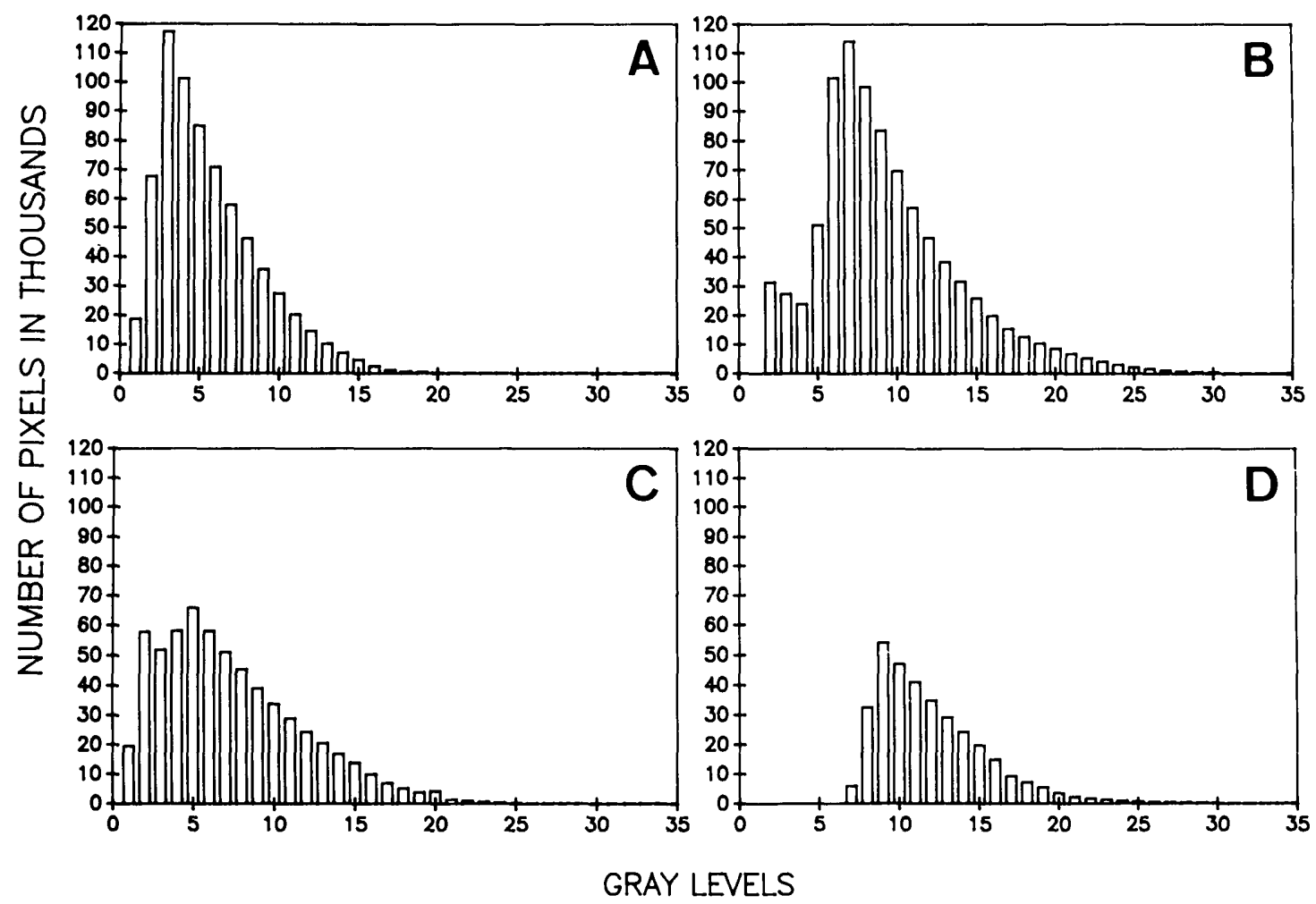

Figure 3. Distributions into classes of increasing gray level of pixels (total of 7 rats) activated by immunocytochemically labeled growth hormone (A-D) in the anterior pituitary glands of young adult (A) and old (B) male and of young adult (C) and old (D) female rats. $p<.01$ young adult vs old (both sexes) and male vs female (both age groups).
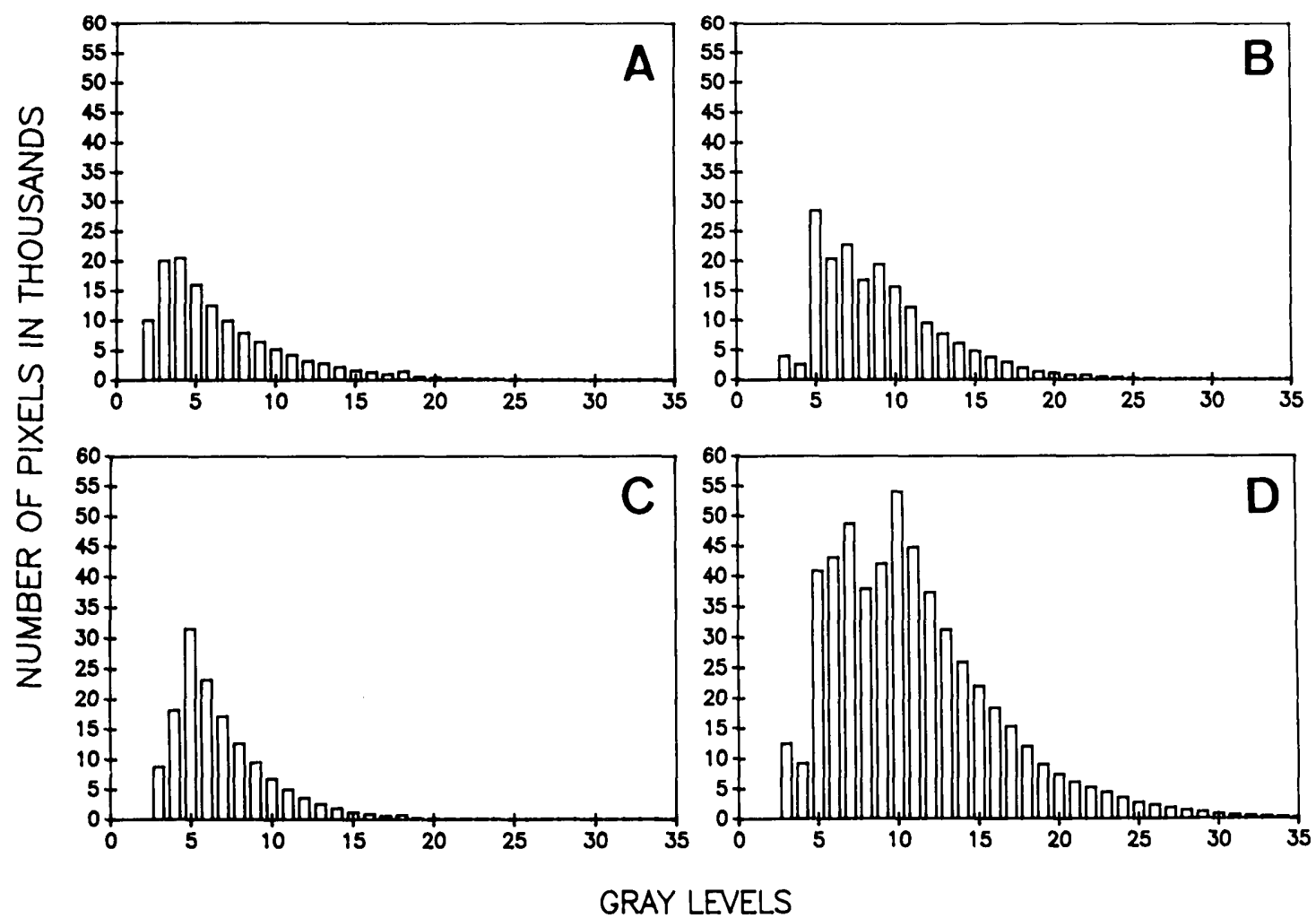

Figure 4. Distributions into classes of increasing gray level of pixels (total of 7 rats) activated by immunocytochemically labeled prolactin (A-D) in the anterior pituitary glands of young adult (A) and old (B) male and of young adult (C) and old (D) female rats. $p<.01$ young adult vs old (both sexes) and male vs female (both age groups). 
reactive material per unit area of tissue, on the contrary, was higher $(p<.05)$ in old female rats.

Immunocytochemistry of lactotropes. - By light-microscopical observation no adenomatous change was observed. PRL-immunoreactive cells appeared to be more numerous both in old (Figure 2B) than in young (Figure 2A) male as well as in old (Figure 2D) than in young (Figure 2C) female rats. In both age groups, female appeared to have more immunolabeled cells than male rats.

By densitometrical PRL evaluation, the total immunoreactivity, number of immunoreactive structures, and area of immunoreactive material per unit area of tissue were slightly higher in old than in young adult male rats; but, because of high individual variations, the $95 \%$ significance level was not reached (Table 2). Also the distribution of pixels into classes of increasing gray level (Figure 4, A,B) was slightly shifted toward classes of higher density in old male rats $(p<$ .01 young adult vs old). The ratio of total immunoreactivity to area of immunoreactive material per unit area of tissue

Table 1. Body, Pituitary, and Brain Weights From Young Adult and Old Male and Female Rats

\begin{tabular}{lllll}
\hline Group & Sex & $\begin{array}{c}\text { Body Weight } \\
(\mathrm{g})\end{array}$ & \multicolumn{1}{c}{$\begin{array}{c}\text { Pituitary } \\
(\mathrm{mg})\end{array}$} & $\begin{array}{c}\text { Brain } \\
(\mathrm{mg})\end{array}$ \\
\hline $\begin{array}{c}\text { Young } \\
\text { adult }\end{array}$ & Male & $372 \pm 4.4$ & $14.6 \pm 0.63$ & $2,127 \pm 22.2$ \\
Old & Male & $614 \pm 16.2^{* *}$ & $21.3 \pm 0.64^{* *}$ & $2,100 \pm 152.0$ \\
Young & & & & \\
$\quad$ adult & Female & $232 \pm 5.4+\dagger$ & $12.3 \pm 0.56 \dagger$ & $1,820 \pm 46.0{ }^{\dagger \dagger}$ \\
Old & Female & $395 \pm 12.1^{* *+\dagger}$ & $27.7 \pm 2.81^{* * \dagger}$ & $2,151 \pm 56.5^{*}$ \\
\hline
\end{tabular}

Values are mean $\pm S E M .7$ rats per group.

${ }^{*} p<.05 ;{ }^{* *} p<.01$ old vs young adult (same sex)

$\dagger p<.05 ; \dagger+p<.01$ female vs male (same age). was higher $(p<.05)$ in old than in young adult male rats (Table 2).

The total immunoreactivity $(p<.01)$, number of immunoreactive structures $(p<.01)$, area of immunoreactive material per unit area of tissue $(p<.01)$, and ratio of total immunoreactivity to area of immunoreactive material per unit area of tissue $(p<.05)$ were higher in old than in young adult female rats (Table 2). Also, the distribution of pixels into classes of increasing gray level (Figure 4, C,D) was clearly shifted toward classes of higher density in old female rats $(p<.01$ young adult vs old).

By comparing the two sex groups, the increase of the total PRL immunoreactivity, number of immunoreactive structures, and area of PRL immunoreactive material per unit area of tissue observed in old compared with young animals was much higher $(p<.01)$ in female rats (Table 2$)$. The number of immunoreactive structures was also higher $(p<.01)$ in young adult female than in male rats (Table 2). Also, the distribution of pixels into classes of increasing gray level (Figure 3, B,D) showed that in all classes the total number of pixels was clearly higher $(p<.01)$ in old female than in male rats.

\section{Discussion}

By light-microscopical observation, the number of pituitary somatotropes appeared to be higher in male than in female rats of both age groups. The number of $\mathrm{GH}$-immunoreactive structures seems to indicate the same. This complies with the higher GH content and synthesis rate in male rats (for literature see Batson et al., 1989) and with the higher GH secretion of cultured male pituitary cells (Batson et al., 1989). Since GRF regulates the number of somatotrope mitoses (Billestrup et al., 1986), the higher hypothalamic GRF present in male rats (Gabriel et al., 1989) may account for the apparently higher number of $\mathrm{GH}$-immunoreactive cells.

Table 2. Densitometrical Quantification of Growth Hormone and Prolactin in Pituitary Glands From Young Adult and Old Male (M) and Female (F) Rats

\begin{tabular}{|c|c|c|c|c|c|}
\hline Group & Sex & $\begin{array}{c}\text { Total } \\
\text { Immunoreactivitya } \\
\text { per } \mu \mathrm{m}^{2} \\
\text { of Tissue } \\
\text { (A) }\end{array}$ & $\begin{array}{l}\begin{array}{c}\text { Number } \\
\text { of }\end{array} \\
\text { Structures } \\
\text { per } \text { mm }^{2} \\
\text { of Tissue }\end{array}$ & $\begin{array}{l}\text { Area of Immunoreactive } \\
\text { Material } \\
\text { per } \mathrm{mm}^{2} \text { of Tissue } \\
\left(\mu \mathrm{m}^{2} \times 10^{-3}\right) \\
\text { (B) }\end{array}$ & $(A / B) \times 10^{3}$ \\
\hline \multicolumn{6}{|c|}{ Growth Hormone } \\
\hline Young adult & $\mathbf{M}$ & $4.10 \pm 0.311$ & $4,432 \pm 181.1$ & $134.2 \pm 9.60$ & $30.5 \pm 0.24$ \\
\hline Old & $\mathbf{M}$ & $5.78 \pm 0.649^{*}$ & $2,813 \pm 268.5^{* *}$ & $176.7 \pm 19.56$ & $32.7 \pm 0.55^{* *}$ \\
\hline Young adult & $\mathrm{F}$ & $3.84 \pm 0.540$ & $2,564 \pm 164.4 \dagger \dagger$ & $121.9 \pm 16.60 \dagger \dagger$ & $31.4 \pm 0.43$ \\
\hline Old & $\mathbf{F}$ & $2.35 \pm 0.370^{*} \dagger \dagger$ & $1,692 \pm 208.2^{* * \dagger \dagger}$ & $68.8 \pm 10.71^{* *}$ & $34.2 \pm 0.14 * * \dagger$ \\
\hline \multicolumn{6}{|l|}{ Prolactin } \\
\hline Young adult & $\mathbf{M}$ & $0.556 \pm 0.069$ & $1,519 \pm 133.9$ & $18.6 \pm 2.35$ & $29.9 \pm 0.15$ \\
\hline Old & M & $0.849 \pm 0.140$ & $2,606 \pm 367.9$ & $27.1 \pm 4.36$ & $31.2 \pm 0.57^{*}$ \\
\hline Young adult & $\mathrm{F}$ & $0.630 \pm 0.085$ & $2,510 \pm 249.1 \dagger \dagger$ & $21.0 \pm 2.90$ & $30.1 \pm 0.16$ \\
\hline Old & $\mathbf{F}$ & $2.610 \pm 0.606^{* * \dagger \dagger}$ & $6,063 \pm 368.6^{* * \dagger \dagger}$ & $80.4 \pm 16.60 * * \dagger \dagger$ & $31.8 \pm 0.73^{*}$ \\
\hline
\end{tabular}

Note. Values are mean $\pm S E M .7$ rats per group.

'Total immunoreactivity $=$ sum of the product of number of pixels times the corresponding gray level.

'Structure $=$ contiguous immunocytochemically labeled areas of the image exceeding a particular density.

${ }^{*} p<.05 ;{ }^{* *} p<.01$ old vs young adult (same sex).

$\dagger p<.05 ; \dagger \uparrow<.01$ female vs male (same age). 
The number of GH-immunoreactive structures was considerably decreased in old rats of both sexes. This could indicate that with increasing age somatotropes become either reduced in number and/or grouped in clusters. This observation is consistent with the age-related reduced number and size of GH-immunoreactive cells found at autopsy in human pituitaries (Sun et al., 1984). A reduced number of somatotropes may be consequent to a defective function of GRFproducing neurons (Ono et al., 1986; Parenti et al., 1987) and reduced number of GRF axon terminals (Morimoto et al., 1988) in aged animals. Moreover, the GRF and GRF mRNA contents in the hypothalamus of old rats are decreased (De Gennaro et al., 1989) while somatostatin is unchanged (Morimoto et al., 1988).

Compared with young adult rats of matching sex, the total GH immunoreactivity and area of immunoreactive material per unit surface of pituitary tissue were increased in old male and decreased in old female rats as confirmed by the pixel distribution into gray level classes.

Thus, the reduced number of GH-immunoreactive structures associated with increased total immunoreactivity and increased area of GH-labeled cytoplasm in old male somatotropes may be explained by a moderately increased cell size which leads to formation of cell clusters. The finding parallels the increased in vitro GH synthesis (Burek and Frohman, 1970) of pituitary cells from old male rats. In old female rats, on the contrary, together with the reduced number of GHimmunoreactive structures also, the total immunoreactivity and area of GH-labeled cytoplasm were reduced. This could indicate that aging generally diminishes the somatotropic function of female rats. Indeed, the $\mathrm{GH}$ content is reduced in the pituitaries of old female rats (Forman et al., 1985).

The number of PRL-immunoreactive structures, which is partly proportional to the number of lactotropes, and the total immunoreactivity were higher in pituitaries from female than male rats of both age groups. This was confirmed by the pixel distribution into gray level classes. A higher number of lactotropes has already been reported in old female rats (Baker et al., 1969; Takahashi and Kawashima, 1982; Chuknyiska et al., 1986) and could be related to the higher estrogen production in this sex.

In old female rats the histological picture of lactotropes resembles the one found after estrogen stimulation (Casanueva et al., 1982). In fact, their pituitaries are exposed to high estrogen levels during the long-lasting constant estrous which precedes the anestrous cycle. Since estrogens are potent activators of the synthesis and release of PRL (Haug, 1979) and lactotrope mitoses (Lloyd et al., 1973), the chronically increased plasma estrogen level is probably responsible for these pituitary changes. Consequently, all PRL measurements greatly increased in our old female rats. This finding corresponds to the higher PRL content previously reported (Cocchi et al., 1986; Bonetti et al., 1987).

Despite the age-related progressively reduced tuberoinfundibular dopaminergic function (Demarest et al., 1980; Gudelsky et al., 1981), PRL measurements were only slightly but, because of high individual variations, not significantly increased in old male rats. This may be explained by a compensatory supersensitivity of DA receptors on the lactotropes, supported both by the increased number of DA binding sites (Govoni et al., 1980) and by increased inhibition of the DA-sensitive cyclase in old male rats (Parenti et al., personal communication).

The pituitaries of our old rats did not show adenomas, yet an appearance compatible with intense PRL synthesis and secretion. This is not surprising, since increased PRL synthesis and secretion are not necessarily related to pituitary tumors (Cocchi et al., 1982). Yet, it is difficult to evaluate to which extent increased estrogen secretion and reduced dopaminergic function may have contributed to these agerelated changes.

Summarizing, we observed an age-dependent diminution of the intracellular GH-immunoreactive material in female but not in male rats. The age-dependent PRL increase, due both to a possibly increased cell number and intracellular hormone content, was present only in female rats. The amount of GH- and PRL-immunoreactive material, distributed into classes of increasing density, differed both between sex and age groups. We thus conclude that the aging process appears to cause sexually dimorphic changes in the rat somatotrope and lactotrope cell populations.

\section{ACKNOWLEDGMENTS}

This work was supported by the Swiss National Science Foundation, grant 3.659-087 (GLR and GEB); by the Berne University Foundation for Research Promotion (Hochschulstiftung) grants 11.6.1985, 25.3.1986, 26.6.1987, 15.6.1988, and 13.6.1989 (GEB); and by the special CNR (Italy) research project 'Preventive and Rehabilitative Medicine,' subproject Mechanisms of Aging, grant 87.00377-56 (EEM and DC).

We thank Ursula Forster, Stephan Grimm, and Giuseppe DiLullo for skillful technical assistance. Miss Maria Lupo provided secretarial assistance.

Address correspondence and reprint requests to Prof. G.L. Rossi, Division of Experimental Pathology, Institute of Animal Pathology, University of Berne, P.O. Box 2735, CH-3001 Berne, Switzerland.

\section{REFERENCES}

Agnati, L. F.; Fuxe, K.; Zoli, M.; Zini, I.; Härfstrand, A.; Toffano, G.; Goldstein, M. Morphometrical and microdensitometrical studies on phenylethanolamine- $\mathrm{N}$-methyltransferase and neuropeptide $\mathrm{Y}$-immunoreactive neurons in the rostral medulla oblongata of the adult and old male rat. Neuroscience 26:461-478; 1988.

Baker, B. L.; Midgley, A. R.; Gersten, B. E., Jr.; Yu, Y. Y. Differentiation of growth hormone- and prolactin-containing acidophils with peroxidase-labeled antibody. Anat. Rec. 164:163-172; 1969.

Batson, J. M.; Krieg, R. J., Jr.; Martha, P. M., Jr.; Evans, W. S. Growth hormone $(\mathrm{GH})$ response to $\mathrm{GH}$-releasing hormone by perifused pituitary cells from male, female, and testicular feminized rats. Endocrinology 124:444-448; 1989.

Berkvens, J. M.; van Nesselrooy, J. H. J.; Kroes, R. Spontaneous tumours in the pituitary gland of old Wistar rats. A morphological and immunocytochemical study. J. Pathol. 130:179-191; 1980.

Bestetti, G. E.; Reymond, M. J.; Perrin, I. V.; Kniel, P. C.; LemarchandBéraud, Th.; Rossi, G. L. Thyroid and pituitary secretory disorders in streptozotocin-diabetic rats are associated with severe structural changes of these glands. Virchows Archiv [B] 53:69-78; 1987.

Billestrup, N.; Swanson, L. W.; Vale, W. Growth hormone-releasing factor stimulates proliferation of somatotrophs in vitro. Proc. Natl. Acad. Sci. USA 83:6854-6857; 1986.

Bonetti, A. C.; Bellini, F.; Calderini, G.; Galbiati, E.; Toffano, G. Agedependent changes in the mechanisms controlling prolactin secretion and phosphatidylinositol turnover in male rats: Effect of phosphatidylserine. Neuroendocrinology 45:123-129; 1987.

Burek, C. L.; Frohman, L. A. Growth hormone synthesis by rat pituitaries in vitro: Effect of age and sex. Endocrinology 86:1361-1367; 1970 
Casanueva, F.; Cocchi, D.; Locatelli, V.; Flauto, C.; Zambotti, F.; Bestetti, G.; Rossi, G. L.; Müller, E. Defective central nervous system dopaminergic function in rats with estrogen-induced pituitary tumors, as assessed by plasma prolactin concentrations. Endocrinology 110: 590-599; 1982

Childs, G. V.; Lloyd, J. M.; Unabia, G.; Gharib, S. D.; Wierman, M. E.; Chin, W. W. Detection of luteinizing hormone B messenger ribonucleic acid (RNA) in individual gonadotropes after castration: Use of a new in situ hybridization method with a photobiotinylated complementary RNA probe. Mol. Endocrinol. 1:926-932; 1987.

Chuknyiska, R. S.; Blackman, M. R.; Hymer, W. C.; Roth, G. S. Agerelated alterations in the number and function of pituitary lactotropic cells from intact and ovariectomized rats. Endocrinology 118:18561862; 1986.

Cocchi, D.; Casanueva, F.; Locatelli, V.; Penalva, A.; Novelli, A.; Bestetti, G.; Rossi, G. L.; Müller, E. E. Pathophysiological aspects of prolactinomas. In: Molinatti, G. M., ed. A clinical problem: microprolactinoma. Diagnosis and treatment. Amsterdam: Excerpta Medica, 1982

Cocchi, D.; Calderini, G.; Ganzetti, 1.; Galbiati, E.; Parenti, M.; Müller, E. E. Aspects of the control of prolactin and growth hormone secretion in aging. In: Müller, E. E.; MacLeod, R. M., eds. Neuroendocrine perspectives, vol. 5. Amsterdam: Elsevier, 1986.

Davies, C.; Jacobi, J.; Lloyd, H. M.; Meares, J. D. DNA synthesis and the secretion of the male rat: effect of diethylstilboestrol and 2-bromo-0ergocryptine metanesulphonate. J. Endocrinol. 61:411-417; 1974

De Gennaro Colonna, V.; Zoli, M.; Cocchi, D.; Maggi, A.; Marrama, P.; Agnati, L. F.; Müller, E. E. Reduced growth hormone releasing factor (GHRF)-like immunoreactivity and GHRF gene expression in the hypothalamus of aged rats. Peptides 10:705-708; 1989.

Demarest, K. T.; Riegle, G. D.; Moore, K. E. Characteristics of dopaminergic neurons in the aged male rat. Neuroendocrinology 31:222$227 ; 1980$.

Forman, L. J.; Sonntag, W. E.; Hylka, V. W.; Meites, J. Pituitary growth hormone and hypothalamic somatostatin in young female rats versus old constant estrous female rats. Experientia 41:653-654; 1985.

Forman, L. J.; Sonntag, W. E.; Miki, N.; Ramos, T.; Meites, J. Comparison of the effects of central acting drugs on prolactin release in young and old male rats. Proc. Soc. Exp. Biol. Med. 167:354-358; 1981.

Gabriel, S. M.; Millard, W. J.; Koenig, J. I.; Badger, T. M.; Russell, W. E.; Maiter, D. M.; Martin, J. B. Sexual and developmental differences in peptides regulating growth hormone secretion in the rat. Neuroendocrinology 50:299-307; 1989

Govoni, S.; Memo, M.; Saiani, L.; Spano, P. F.; Trabucchi, M. Impairment of brain neurotransmitter receptors in aged rats. Mech. Ageing Dev. 12:39-46; 1980.

Gudelsky, G. A.; Nansel, D. D.; Porter, J. C. Dopaminergic control of prolactin secretion in the aging male rat. Brain Res. 204:446-450; 1981

Haug, E. Progesterone suppression of estrogen-stimulated prolactin secretion and estrogen receptor levels in rat pituitary cells. Endocrinology 104:429-437; 1979.

Kovacs, K.; Horvath, E.; Ilse, R. G.; Ezrin, C.; Ilse, D. Spontaneous pituitary adenomas in aging rats. A light microscopic, immunocytological and fine structural study. Beitraege zur Pathologie 161:1-16; 1977.
Lloyd, H. M.; Meares, J. D.; Jacobi, J. Early effects of stilboestrol on growth hormone and prolactin secretion and on pituitary mitotic activity in the male rat. J. Endocrinol. 58:227-231; 1973.

Lloyd, J. M.; Childs, G. V. Differential storage and release of luteinizing hormone and follicle-releasing hormone from individual gonadotropes separated by centrifugal elutriation. Endocrinology 122:1282-1290; 1988.

Meites, J. The neuroendocrinology of hypothalamic aging. In: Müller, E. E.; MacLeod, R. M., eds. Neuroendocrine perspectives, vol. 5. Amsterdam: Elsevier, 1986.

Morimoto, N.; Kawakami, F.; Makino, S.; Chihara, K.; Hasegawa, M.; Ibata, Y. Age-related changes in growth hormone releasing factor and somatostatin in the rat hypothalamus. Neuroendocrinology 47:459-464; 1988

Müller, E. E.; Nistico, G.; Scapagnini, U. Neurotransmitter and anterior pituitary function. New York: Academic Press, 1977.

Ono, M.; Miki, N.; Shizume, K. Release of immunoreactive growth hormone-releasing factor (GRF) and somatostatin from incubated hypothalamic slices in young and old male rats. Neuroendocrinology (Suppl.) 43:111; 1986.

Parenti, M.; Dall Ara, A.; Rusconi, L.; Cocchi, D.; Müller, E. E. Different regulation of growth hormone-releasing factor-sensitive adenylate cyclase in the anterior pituitary of young and aged rats. Endocrinology 121:1649-1653; 1987.

Pradahan, S. N. Central neurotransmitters and aging. Life Sci. 26:1643$1656 ; 1980$.

Rossi, G. L.; Bestetti, G. Technical aspects in the study of pathologic lesions in the hypothalamus of the rat. In: Jones, T. C.; Mohr, U.; Hunt, R. D., eds. Monographs on pathology of laboratory animals, endocrine system. Berlin: Springer-Verlag, 1983.

Rudman, D.; Kutner, M. H.; Rogers, C. M.; Lubin, M. F.; Fleming, G. A.; Pain, R. P. Impaired growth hormone secretion in the adult population. J. Clin. Invest. 67:1361-1369; 1981.

Shibasaki, T.; Shizume, K.; Makahara, M.; Masuda, A.; Ibiki, K.; Demura, H.; Wakabayashi, I.; Ling, N. Age-related changes in plasma growth hormone response to growth hormone releasing hormone in man. J. Clin. Endocrinol. Metab. 58:212-214; 1984.

Simpkins, J. W.; Mueller, G. P.; Huang, H. H.; Meites, J. Evidence for depressed catecholamine and enhanced serotonin metabolism in aging male rats: Possible relation to gonadotropin secretion. Endocrinology 100:1672-1678; 1977.

Sonntag, W. E.; Forman, L. J.; Meites, J. Changes in growth hormone secretion in aging rats and man, and possible relation to diminished physiological functions. In: Meites, J., ed. Neurobiology of aging. New York: Plenum Press, 1983

Sun, Y. K.; Xi, Y. P.; Fenoglio, C. M.; Pushparaj, N.; O'Toole, K. M.; Kledizik, G. S.; Nette, E. G.; King, D. W. The effect of age on the number of pituitary cells immunoreactive to growth hormone and prolactin. Hum. Pathol. 15:169-180; 1984.

Takahashi, S.; Kawashima, S. Age-related changes in prolactin cell percentage and serum prolactin levels in intact and neonatally gonadectomized male and female rats. Acta Anatomica 113:211-217; 1982.

Received December 26, 1989

Accepted October 31, 1990 